\title{
Criminal Geropsychology-The Nexus of Elderly Offending, Mental Disorders, and Victimization
}

\author{
Raqota Berger \\ Center for Criminal and Psychological Studies, Los Angeles, USA \\ Email: rberger@vcccd.edu
}

How to cite this paper: Berger, R. (2019) Criminal Geropsychology-The Nexus of Elderly Offending, Mental Disorders, and Victimization. Voice of the Publisher, 5, $35-48$.

https://doi.org/10.4236/vp.2019.53003

Received: August 15, 2019

Accepted: September 24, 2019

Published: September 27, 2019

Copyright (อ 2019 by author(s) and Scientific Research Publishing Inc. This work is licensed under the Creative Commons Attribution International License (CC BY 4.0).

http://creativecommons.org/licenses/by/4.0/

\section{(c) (i) Open Access}

\begin{abstract}
The population of the United States is aging. As the overall numbers of those aged 65 years and older continues to swell there will be an increasing need to pay close attention to crime and criminal offending among the elderly population. Elderly adults are involved in a range of offending behaviors, from violent crimes, to substance use offenses, to white-collar crimes (e.g. fraud and embezzlement). The fastest growing segment of the prison population is geriatric offenders. Older inmates have many special needs and they cost taxpayers around 3 times as much to incarcerate than younger offenders. This project analyzed survey and interview data collected from 237 research participants. The collected information provided valuable insight into people's thoughts, knowledge, and experiences with elderly criminal offending. At the heart of the undertaking was the thorough examination of the emerging field of criminal geropsychology. This specialized area of study will continue to become more relevant and central to the study of aging, criminal behavior, and victimization. Criminal geropsychology is a valuable academic and applied area of study that focuses on elderly offending and victimization. Criminal geropsychology complements a number of fields that also study and work with aging populations, such as clinical psychology, forensic psychology, criminology, corrections, gerontology, psychiatry, and the law.
\end{abstract}

\section{Keywords}

Elderly Offending, Criminal Behavior, Mental Disorders, Incarceration, Victimization

\section{Introduction}

Geropsychology is a subdiscipline within the larger field of psychology that has 
been steadily growing. Geropsychology traditionally focuses on matters pertaining to the cognitive, physical, and developmental changes that take place as one grows older. In the field of gerontology, 65 years of age is traditionally regarded as the age whereby one becomes an "older" adult. Some examples of core areas of concern in geropsychology involve studying the aging process, changes in brain functioning, social and interpersonal loss, mental illness, health care, etc. Geropsychology as an applied concentration of interest is only going to become more relevant and significant over time. One of the main reasons for this is due to the fact that the world's human population is aging. It is estimated that by the year 2050 there will be more than 2 billion people aged 60 and older on this planet [1]. In the United States alone it is estimated that by the year 2030 there will be over 72 million adults aged 65 and over. It is also estimated that the average lifespan in 2030 will be 80 years of age. This will constitute around $20 \%$ of the entire American population [2]. This type of aging trend has never been seen throughout history. As nations around the world become more modernized it only makes sense that the world's aging population will continue to grow. With this being the case, it also makes sense that the study of aging will also grow right along with it.

As the elderly population continues to grow larger a new subspecialty will also become more pertinent and demanding of both academic and applied attention-criminal geropsychology. This concentrated specialty focuses its efforts on matters pertaining to elderly criminal behavior, mental illness, substance abuse and addiction, incarceration, treatment of offenders, violence, and victimization. Criminal geropsychology will increasingly become more germane across many scholarly disciplines and professions, such as criminology, psychology, psychiatry, corrections, and gerontology. This work will set out to explain this developing and increasingly important concentration that specifically focuses on elderly offending and victimization. Relevant and current data will be provided to assist the reader in better understanding this emerging field of study and why it matters. Evidence will also be provided regarding people's experiences and thoughts about elderly criminal offending.

\subsection{Criminal Geropsychology and Offending Behaviors}

Within the field there are discrepancies about what constitutes "old age". Scholars and professionals have their own thoughts on where the age line is drawn and it usually revolves around the ages of 55, 60, and 65 [2] [3] [4] [5]. Much of this comes down to operationalization and how each researcher or practitioner conceptualizes the onset of old age. Regardless of where the line is set, there are some clear trends taking place among the elderly population in regard to criminal offending. Due to the increasing numbers in the elderly population, the American Psychological

Association predicts that there will be a need for more than 5000 specialists in geropsychology by 2020 [6]. Much of this increase in demand will be connected 
to mental health issues, substance abuse issues, incarceration, and offending behaviors. Although the elderly are less likely overall to engage in offending behaviors due to things such as burnout, less rebellious tendencies, less peer pressure, and maturity, the overall rates of offending are going up simply due to increasing population numbers [7]. According to Gross [2], the most common types of crimes committed by the elderly are alcohol-related (e.g. driving under the influence). The data presented in this study also showed that both violent offending and drug abuse crimes are increasing among the elderly population [2]. Research by Barack et al. [4] studying criminal offenders aged 65 years and older found that $43 \%$ of the crimes were of a financial nature, whereas violent crimes accounted for approximately $11 \%$ of the crimes committed. Additional research looking at the trends in elderly offending also found that white-collar (e.g. fraud, embezzlement, tax evasion), alcohol, and drug offenses were the leading crimes committed by the elderly [8] [9]. Driving under the influence of alcohol and/or drugs (including prescription drugs) continues to be a leading problem among this population.

There are differing thoughts as to why elderly folks may engage in criminal behaviors. Some argue that it has to do with mental health issues (e.g. depression), whereas others argue that it has to do with social isolation, low self-control in late life, and/or cognitive impairment [10] [11] [12]. In regard to competency to stand trial, Damakis [13] pointed out that evaluating older adults is particularly difficult due to their increased rates of cognitive impairment and dementia (e.g. Alzheimer's disease). It appears as though certain older individuals are at increased risk of offending due to mental health and cognitive declines [3] [8]. Judgment, self-control, and assessment can all be skewed in those that are suffering from any kind of significant mental and intellectual impairment. Heck and Vauter [14] examined the complex relationship between cognitive impairment and criminal responsibility. In their work they found that elderly offenders are often suffering from one or more mental illnesses, such as affective disorders, psychotic disorders, frontotemporal disorder, Alzheimer's disease, etc. Other researchers have connected criminal offending among those aged 65 and older to social and economic factors (e.g. poverty), life circumstances, and routine activities [15] [16]. Either way, there is a complex and diverse array of reasons that older people commit criminal acts. Criminal geropsychologists need to pay close attention to all of this when they are working with this particular population.

\subsection{Aging Prison Population and Incarceration}

One of the most important areas revolving around elderly offending concerns the growing numbers of inmates over 55 in state and federal prisons and jails. Due to the stressful nature of incarceration it is generally believed that inmates are often 10 years older biologically than they are chronologically. This is why inmates aged 55 and older are regarded as an elderly and "special population" [2] [5]. Older inmates constitute the fastest growing segment of the prison pop- 
ulation and there are many reasons why this is important to pay close attention to. For one thing, older inmates cost taxpayers around 3 times as much as younger inmates due to health expenditures alone [1] [11]. Older inmates are also more likely to be suffering from some type of mental illness, such as dementia, affective disorders, and psychotic disorders [11] [14]. Inmates over 55 also have significantly higher rates of cardiac and neurological disorders [17]. Other matters of concern regarding older inmates involve chronic health problems (e.g. arthritis, emphysema), victimization, and suicide [2] [8] [17]. Older inmates that are mentally or physically compromised are more likely to be assaulted while incarcerated than the average younger inmate.

The number of elderly offenders is growing significantly across both state and federal prisons. Older men and women constitute the fastest growing proportion of the prison population in most nations [17]. In the United States it is believed that by 2030 nearly $35 \%$ of all inmates will be labelled as geriatric [2]. According to Davoren et al. [17], between the years 2007 and 2010 the United States prison population of inmates 65 years of age and older grew 94 times faster than the total sentenced prison population. In 2010, inmates 55 and older constituted just under $10 \%$ of the total American prison population. The proportion of elderly inmates more than doubled between 1990 and 2000 [11] and it has only gotten significantly larger since that time [17]. That number doubled once more between 2000 and 2010 [1]. The larger trends in elderly offending and incarceration rates, along with the massive overall increase in population numbers, makes this a critically important social, cultural, political, and economic matter [1] [2] [12].

\subsection{Domestic Violence, Sexual Assault, and Victimization}

Interpersonal violence is a leading problem among older adults and it often goes unreported [12]. There are various reasons that older adults are less likely to report than younger adults, including fear, shame, stigmatization, vulnerability, embarrassment, mental illness, and cognitive impairment [6] [7] [12]. These factors also make it less likely that older adults will be arrested than younger adults for committing similar offenses [7]. Many instances of domestic violence and sexual assault among the elderly also involve drugs and/or alcohol. Although older women are less likely to be sexually or physically assaulted than younger women, they are also less likely to report or admit that they have been victimized [12]. Some of these women may fear not being able to take care of themselves financially, or they feel like they do not have anyone to turn to, therefore they are less likely to bring this to the attention of others. Although most elderly crimes are nonviolent in nature, sexual assault is a reality for many elderly women - as well as for some elderly men, such as those that are incarcerated. Although mental illness and substance abuse is positively correlated with domestic violence and sexual assault, researchers have found that some high functioning elderly men (i.e. with no mental illness) do rationally plan their violent sexual attacks [18]. Interpersonal violence is a problem among the elderly and it often goes 
unreported. Elderly men and women are at increased risk of being victimized due to a variety of reasons, such mental illness, physical health declines, lack of support, social isolation, pride, fear, and so forth. They are also less likely to report their victimization, which places them at an even higher risk of being harmed or taken advantage of. Criminal geropsychologists need to pay close attention to this more hidden and secretive problem among the elderly population.

\subsection{Homicide among the Elderly}

Generally speaking, homicide is rare among the elderly population when compared to the younger population [19]. Although older offenders convicted of murder are less likely to have a personality disorder than younger offenders convicted of murder, they are much more likely to have some kind of mental illness (e.g. depression, dementia, cognitive impairment, etc.). According to Putkonnen et al. [20] older offenders that have committed murder are also more likely to have some kind of physical impairment or disability, although they are less likely to have diagnosable psychopathy and tend be less socially deviant. The routines activities approach places elderly homicide at the center of circumstance. This basically means that when older offenders kill others it tends to be due more to suitability (e.g. easy victim in the home) than to an outwardly planned attack against a stranger [16]. Elderly homicide offenders are less likely to have prior records before committing their acts than younger offenders.

Both elderly men and women are more likely to kill intimate partners than they are to kill strangers or those that they are loosely affiliated with [19]. Elderly offenders are also more likely to kill for emotional reasons that for instrumental reasons (e.g. killing someone for their purse or wallet). Around $2.5 \%$ of all homicides are committed by the elderly and these rates are expected to go up as the elderly population increases [21]. Older offenders are more likely to kill their spouse or family member via strangulation/suffocation than younger offenders. When older men and women kill it is often more spontaneous than it is planned [8]. It is also not uncommon for an elderly family member to kill an ailing spouse to end their suffering [21]. As homicide rates rise due to the massive increase in the elderly population it will become even more essential that criminal geropsychologists learn as much as they can about the risk factors, causes, and methods of elderly homicide.

\subsection{Suicide in the Elderly Population}

Elderly suicide rates are among the highest in the population. Elderly suicide rates are particularly high for elderly males. Increasing suicide and self-harm rates among the elderly are believed to be directly connected to medical illness, increasing loss of social support, social isolation, depression, hopelessness, and infirmity [17] [22]. Elderly men and women that are facing or dealing with chronic health problems, severe mental illness, declining overall health, and/or are facing death are at increased risk of taking their own lives [8]. Older men 
and women that are abusing alcohol and/or drugs are also at increased risk of self-harm and committing suicide [5] [22]. Older men and women today are also reporting higher rates of social isolation and loneliness than in the past and this is also closely connected to thoughts of suicide and self-harming behaviors. Block [19] found that the elderly are more likely to commit suicide than younger adults. This is particularly true when they are socially alienated, suffering from severe depression, are abusing substances, or are suffering from chronic pain. A particularly concerning time is after the loss of a spouse. Many elderly men will take their own lives shortly after the death of their spouse. As the elderly population grows in numbers it will become increasingly important to monitor the health and functioning of older adults that are at risk of self-harm or taking their own lives. This is a critical component to the field of criminal geropsychology.

\subsection{Substance Abuse and the Elderly}

Substance abuse and addiction, including the overuse and abuse of prescribed drugs, has become a serious problem across the United States. It is estimated that almost 1 in 7 Americans are taking some kind of antidepressant alone, which comes to over 3.5 billion doses each year [23]. The highest rates of prescription drug use (e.g. multiple prescriptions, dosing, etc.) are associated with the elderly. Prescription drugs, particularly those associated with painkillers, now account for the majority of deaths from drug overdoses in the United States. A study conducted by the Association for the Advancement of Retired Persons [24] found that $80 \%$ of all Americans 65 years of age and older were taking at least 2 different prescription drugs. The findings also revealed that $50 \%$ of those 65 and older were taking 4 or more different prescription medications. All of these drugs can produce unwanted and harmful side effects. These drugs can also potentially produce harmful interaction effects that can take a major toll on the body's organs. This type of behavior also often leads to addition and overdosing. Researchers looking at the problem with substance use among the elderly have found that substance use/abuse is highly correlated with subsequent criminal behaviors, arrest, and incarceration [2] [3] [9]. Alcohol abuse has also become a serious problem with elderly men and women and is also associated with various health, legal, and social problems [3] [7]. The problem with substance abuse and addiction is only getting worse and the demand for professionals in this area is only going to increase over time. It is predicted that the need for substance abuse treatment for older adults in the United States will double between 2010 and 2020 [6]. Substance abuse and addiction is a major problem that is associated with many social, mental, physical, interpersonal, cultural, and legal problems. Criminal geropsychologists must pay close attention to this on-

going problem and they should learn as much as they can about what is taking place with this across all levels.

\section{Empirical Evidence to Ground the Topic}

To better understand the theme of interest and concerns of criminal geropsy- 
chology, information was obtained from 237 American participants. Information was gathered in a nonprobabilistic manner through both survey research and semi-structured interviews. The respondents were asked about their knowledge and experiences with elderly individuals that are 60 years of age and older. To be eligible to participate in the study respondents needed to be at least 18 years of age. No compensation was given for filling out the survey or for participating in an interview. There were no conflicts of interest in this study and no deception was used. Consent was given by the respondents through their willingness to answer the various research questions, to fill out the survey, and to be interviewed. Confidentiality was provided to all participants and no personally identifiable information has been included in the final report. All participants filled out the survey in a manner that was deemed to be valid and honest. Respondents appeared to be clear on what the topic was about and what they were being asked. If a respondent needed any clarifying information, it was given to them at the same time that they were filling out the survey. No surveys included in the final analysis contained blatantly false or misleading data. The survey was quantitative in nature and collected data on all 4 levels of measurement. Both discrete and continuous data was gathered to allow for a range of statistical analyses and groups comparisons (e.g. age cohorts, ethnicity, gender, etc.). The interviews were only conducted with certain participants that were over the age of 60. The interviews provided additional insight into the lived experiences and knowledge of elderly respondents.

The final sample consisted of 50 respondents that were 60 years of age and older (21\%), 40 respondents between the ages of 40 to 59 (17\%), 124 respondents between the ages of 20 to 39 (52\%), and 23 respondents that were between 18 and 19 years of age (10\%). Women made up 56\% of the sample, and men made up the remainder (44\%). Hispanic respondents made up the bulk of the respondents $(n=151,63.7 \%)$. Although this is somewhat skewed toward this demographic, Hispanics make up the largest percentage of the population in the general region where the data were collected (i.e. primarily Los Angeles county). The remainder of the sample was White $(n=49,20.7 \%)$, Black $(n=16,6.8 \%)$, Asian $(n=14,5.5 \%)$, and Other $(n=8,3.4 \%)$. In certain instances, some groups needed to be eliminated from specific statistical analyses due to the nature of the final sample size (e.g. Other). In the end, the final sample and collected data provided valuable information that was both useful and relevant to the topic at hand.

\subsection{Analysis and Findings}

When asked if respondents personally knew any elderly adult that has committed a criminal act, $35 \%$ stated that they did. Most of the respondents, when asked or interviewed, did not take into consideration minor offenses (e.g. driving without a license, taking prescription drugs that were not their own, etc.). When probed further it did appear that more interviewees altered their thoughts on 
this question and did know of others that have committed some kind of criminal act. When asked about the types of crimes that the elderly are most likely to commit, the most frequently reported criminal act involved some kind of white-collar crime (44.7\%). This was easily the top category of crime, as the second leading type of crime was theft/stealing (19\%), followed by sex crimes (7.6\%), motor vehicle crimes (7.2\%), and violent crimes (5.1\%). Less common crimes identified included domestic violence, drug and alcohol offenses, property crimes, robbery, kidnapping, child support, and suicide. White-collar crime is often regarded as one of the most common among the elderly as issues with fraud, tax evasion, money laundering, embezzlement, etc., continue to climb among this particular growing population. Approximately $30 \%$ of the respondents personally knew at least one elderly man that has committed some type of crime. Violent type of crime was the most common, followed by white-collar, then drugs and alcohol. Only $14 \%$ of the respondents personally knew one or more elderly women that have engaged in some type of criminal act. When it came to elderly female offenders, drug and alcohol and white-collar crimes were the top two types of crime categories reported.

Although the respondents generally felt that younger people were more likely to commit crimes than older people (62\% felt that they were, whereas $13.5 \%$ felt that they were not), when it came specifically to white-collar crimes the sentiment changed (65\% felt that older people are more likely, whereas $13.5 \%$ disagreed with this). The clear majority of participants felt that younger people are more likely to engaged in street crimes (78.5\%; only $7.2 \%$ disagreed with this sentiment). When asked if they felt whether or not crime rates among the elderly were going to increase over time, approximately 6 out 10 respondents believed that they will. Respondents categorized as "Other" were the most likely to feel that crime rates are going to increase among the elderly over time $(80 \%)$, followed by Asian (84.6\%), White (75.5\%), Hispanic (53\%), and Black (31\%). Black respondents were the only group to not feel that crime rates are going to increase in the elderly population. As far as gender, $62.1 \%$ of the women believed that crime will increase, and $54.4 \%$ of the men share this sentiment.

When asked about personal knowledge of elderly offenders, the youngest respondents seem to personally know the highest average number of offenders ( $M$ $=3.17, \mathrm{SD}=5.43)$, followed by those in their 70's $(\mathrm{M}=2.73, \mathrm{SD}=4.00), 50$ 's $(\mathrm{M}$ $=2.68, \mathrm{SD}=4.93), 60$ 's $(\mathrm{M}=1.57, \mathrm{SD}=2.23)$, and 80 's $(\mathrm{M}=1.50, \mathrm{SD}=2.12)$. The rest of the age cohorts knew less than 1 elderly offender on average. It is interesting to see that the youngest individuals claim to personally know the highest number of elderly offenders. This may have to do with the openness that many young people have about certain offending behaviors (e.g. drug use). Men knew more elderly offenders on average than women $(\mathrm{M}=1.70, \mathrm{SD}=3.74 ; \mathrm{M}=$ $1.02, \mathrm{SD}=2.39$, respectively). Respondents that identified as "Other" had the highest numbers when it came to personally knowing elderly offenders ( $\mathrm{M}=$ $3.80, \mathrm{SD}=5.36)$. This was followed by Black $(\mathrm{M}=2.88, \mathrm{SD}=5.02)$, White $(\mathrm{M}=$ 
$1.31, \mathrm{SD}=2.60)$, Hispanic $(\mathrm{M}=1.11, \mathrm{SD}=2.92)$, and Asian $(\mathrm{M}=0.62, \mathrm{SD}=$ $1.26)$.

\subsection{Inferential Findings}

When looking at how those from different age cohorts felt about older people being more likely to commit crimes than younger people an analysis of variance test produced significant group differences, $F(7,229)=2.26, p=0.030$. A number of groups differences were detected through post hoc comparisons. Some differences worth noting include people aged 18 to 19 compared to those in their 60 's (LSD sig. $=0.022$ ), and those in their 20's compared to respondents in their 60 's (LSD sig. $=0.011$ ). Younger respondents were more likely to think that elderly people are more likely to commit crimes than younger people. White-collar crimes among the elderly had a major impact on this finding. Respondents in their 40's also differed from those in their 50's (LSD sig. $=0.011$ ) and those in their 60's (Tukey HSD sig. $=0.030$, Bonferroni sig. $=0.039$ ). Those in their 40's felt that older people were also more likely to commit criminal acts than both those in their 50's and those in their 60's. When it came to white-collar crime the younger respondents were more likely to feel that elderly people were more likely to commit these types of crimes. An ANOVA test produced a significant finding, $\mathrm{F}(7,229)=2.33, \mathrm{p}=0.026$. Respondents aged $18-19$ were generally more likely to feel this way than those in their 60's (LSD sig. $=0.033$ ) and those in their 70's (LSD sig. $=0.024$ ). Respondents in their 20's also felt the same way when compared to respondents in their 60's (LSD sig. $=0.005$ ) and 70's (LSD sig. $=0.012$ ). Those in their 40's significantly differed from those in their 70's (LSD sig. $=0.035$ ). Based on the data it appears that those above 60 years of age tend to think that older people are generally less likely to commit crimes than younger people, whereas many younger respondents, especially those under 50 , have a different perspective on this.

In regard to ethnic differences, an analysis of variance test produced a statistically significant finding, $\mathrm{F}(5,231)=2.43, \mathrm{p}=0.036$. Group differences were detected between Hispanic and Black respondents (Bonferroni sig. $=0.020$, Tukey HSD sig. $=0.016)$. It would appear that Hispanic respondents are more likely to believe that older people are more likely to commit crimes than young people. White respondents were also more likely to share this sentiment when compared to Black respondents (LSD sig. $=0.007$ ), as were respondents categorized as "Other" when compared to Black respondents (LSD sig. = 0.046). An independent samples median test of difference produced significant findings in regard to respondents feeling that older people are more likely to commit crimes than younger people, $\mathrm{M}(5)=12.65, \mathrm{p}=0.027$. The median of Black respondents was significantly below the medians of the other groups in the study. That is, Black respondents did not generally feel that older respondents were more likely to commit crimes than younger respondents. A Kruskal-Wallis test produced similar findings when looking at differences across groups, $\mathrm{H}(5)=12.92, \mathrm{p}=0.024$. 
Again, Black respondents had a significantly different distribution that the other groups in the study when it came to attitudes about elderly offending compared to younger people committing criminal acts.

\subsection{Distribution Free, Directional, and Symmetric Measures}

When asked whether or not they believed that rates of elderly offending would go up as the population ages, a chi-square test produced significant differences in regard to ethnicity, $\mathrm{X}^{2}(5)=19.961, \mathrm{p}=0.01$. Asian, White, and "Other" respondents were much more likely to feel this way than Black respondents. Hispanic respondents were also more likely than Black respondents to feel this way, but they were not quite as resolved about this as the respondents from the other groups. Nominal by nominal measures produced significant correlations between ethnicity and feelings about increasing crime rates among the elderly $(\mathrm{V}=$ $\left.0.290, \mathrm{p}=0.001, \mathrm{~T}_{\mathrm{b}}=0.084, \mathrm{p}=0.001\right)$. Correlational measures analyzing the relationship between gender and elderly male offenders produced significant findings as well $\left(T_{b}=0.026, p=0.015\right)$. These findings suggest that men are more likely to personally know elderly offenders than women are. This may possibly have something to do with differential association and/or men being more likely to be involved in certain types criminal behaviors than women.

\section{Discussion on the Topic and Findings}

This work has set out to bring forth the growing importance of criminal geropsychology as a specialization within the larger field of psychology. Criminal psychologists, clinical psychologists, forensic psychologists, and social psychologists would all benefit from paying close attention to, and learning more about, this increasingly relevant concentration. Criminal geropsychology is also a relevant area of study for those working within the fields of gerontology, criminology, corrections, psychiatry, and law. As the population of elderly men and women continues to grow around the world it is going to become even more critical for those working in both academic and applied fields to pay close attention to the social, cultural, and behavioral trends that are taking place. The elderly population in the United States is growing at an increasing rate and it is expected that there will be more than 72 million men and women aged 65 and older within the next 10 years [2]. As this population grows larger it only makes sense that there will also be a corresponding increase in overall crime rates. It is not that elderly individuals are becoming more crime prone; it is simply a matter of swelling population numbers. Those interested in studying criminal geropsychology in an academic setting, as well as those that are interested in more applied areas, should be heedful of all of the problem areas covered earlier in this work, such as crime rates, incarceration rates, issues and concerns with elderly inmates, violent offending, homicide, suicide, illicit drug and alcohol abuse and addiction, prescription drug abuse and addiction, victimization, sex crimes, domestic violence, mental health issues, treatment of offenders, etc. 
Based on the findings of the collected data it appears that most people do believe that crime among the elderly is going to increase over time. Although the majority of respondents did not believe that older people are more likely to commit crimes overall when compared to younger people, most did take the position that older people are more likely to commit white-collar crimes. It will be particularly important for criminal geropsychologists to mindful of some of the most common types of crimes that the elderly may commit, such as fraud and embezzlement. Many older men and women are in positions of power (e.g. executives, business owners, etc.) and elderly individuals do tend to have more wealth than young people, so it makes sense that this will be an especially salient area of concern. The growing problem with prescription drug abuse and addiction also needs much more attention. It will crucial that professionals working in this area work to change laws, policies, and medical practices that have contributed to the massive problem we are now seeing in the United States concerning prescription drug addiction, overdoes, and death.

Other important matters learned through this research concerns how oblivious most seem to be when it comes to elderly offending. Most of the respondents did not seem to give much thought to elderly criminal behavior until they were asked about it. Upon reflection almost all of them could think of someone they knew that has engaged in some kind of criminal act. It is not that most of the acts were staggeringly serious (e.g. felonies), but they were against the law (e.g. driving on a suspended license). Interviewing elderly participants also enabled a deeper understanding of the quantitative data. For example, almost all of the elderly interviewees stated that older people tend to be much more secretive about their misdeeds or criminal behaviors. This would make sense when one takes into consideration how younger people (e.g. those in their teens and 20 's) are often boisterous about their deviant behaviors (e.g. sharing of illegal drugs, driving while intoxicated, fighting at parties, theft, and so forth). Based on this strong consensus among interviewees it is very likely the case that elderly offending is even significantly higher than what could be revealed through survey data. It is also known that elderly men and women are less likely to be arrested than younger people, even for similar acts [7] [17]. Older men and women are also less likely than younger adults to report being the victim of any particular type of crime [1] [12]. These are all matters that criminal geropsychologists need to be aware of, and account for, in their practice and reporting.

The findings of the study are limited in several ways. Additional research on this topic would benefit from collecting more data from individuals 60 years of age and older. The majority of participants were under 60 years of age (79\%). This limits certain inferential findings that can be made from this study regarding the perspectives and experiences of the elderly themselves. The study is also analytically limited due to the quantitative nature of the bulk of data collected. The design of the study did not allow for in-depth explanations from participants or for contextual understanding of elderly offending or victimization. 
Further research could benefit from incorporating a more qualitative-based inquiry to help better understand the secrecy and realities of elderly offenders and victims. Criminal offending among the elderly is a very complex matter that requires researchers and practitioners alike to pay close attention to the intersection of factors that all play into this increasingly important legal, social, cultural actuality.

\section{Conclusion}

People are living longer than they did in the past. This is especially true in modernized nations such as the United States, where it expected that around 1 out of 5 citizens will be over the age of 65 within the next 10 years. Populations are aging across many nations around the world and it is believed that this global trend is going to continue as science, medicine, and healthcare continue to advance. As these aging trends continue around the planet it will become even more essential to pay assiduous attention to crime, criminal offending, and victimization among the elderly. The field of criminal geropsychology is specifically designed for this purpose. Criminal geropsychology is a relevant and necessary field of study for those working in any discipline concerned with aging. Criminal geropsychology is an instructive and complementary specialization of use to clinical psychologists, forensic psychologists, criminologists, psychiatrists, social psychologists, lawyers, and sociologists.

\section{Conflicts of Interest}

The author declares no conflicts of interest regarding the publication of this paper.

\section{References}

[1] Aliustaoglu, S.F., Ozdemir, M., Ince, H., Yazici, Y.A., Ince, N. and Oral, G. (2011) Criminal Activities of the Elderly in Turkey during the Years 2000-2005. Archives of Gerontology and Geriatrics, 53, 267-270. https://doi.org/10.1016/j.archger.2010.11.028

[2] Gross, B. (2007) Elderly Offenders: Implication for Corrections Personnel. The Forensic Examiner, 1, 56-61.

[3] Wong, M.T., Lumsden, J., Fenton, G.W. and Fenwick, P.B. (1995) Elderly Offenders in Maximum Security Mental Hospital. Aggressive Behavior, 21, 321-324. https://doi.org/10.1002/1098-2337(1995)21:5<321::AID-AB2480210502>3.0.CO;2-5

[4] Barak, Y., Perry, T. and Elizur, A. (1995) Elderly Criminals: A Study of the First Criminal Offense in Old Age. International Journal of Geriatric Psychiatry, 10, 511-516. https://doi.org/10.1002/gps.930100611

[5] Feldmeyer, B. and Steffensmeier, D. (2007) Elder Crime: Patterns and Current Trends, 1980-2004. Research on Aging, 29, 297-322.

https://doi.org/10.1177/0164027507300802

[6] All Psychology Careers (2019) What Is Geropsychology? https://www.allpsychologycareers.com/topics/geropsychology.html

[7] Lindesay, J. (1996) Elderly People and Crime. Reviews in Clinical Gerontology, 6, 
199-204. https://doi.org/10.1017/S0959259800004664

[8] Aday, R.H. (1994) Aging in Prison: A Case Study of New Elderly Offenders. International Journal of Offender Therapy and Comparative Criminology, 38, 79-91. https://doi.org/10.1177/0306624X9403800108

[9] Petersen, D. (1988) Substance Abuse, Criminal Behavior, and Older People. Journal of the American Society on Aging, 12, 63-67.

[10] Wolfe, S.E. (2015) Low Self-Control, Gender, Race, and Offending in Late Life. Psychology, Crime, and Law, 21, 426-451. https://doi.org/10.1080/1068316X.2014.989169

[11] Yorston, G.A. and Taylor, P.J. (2006) Commentary: Older Offenders-No Place to go? Journal of the American Academy of Psychiatry and the Law, 34, 333-337.

[12] Acierno, R., Brady, K., Gray, M., Kilpatrick, D.G., Resnick, H. and Best, C.L. (2002) Psychopathology Following Interpersonal Violence: A Comparison of Risk Factors in Older and Younger Adults. Journal of Clinical Geropsychology, 8, 13-23. https://doi.org/10.1023/A:1013041907018

[13] Demakis, J.G. (2018) Assessment and Restoration of Competency to Stand Trial with Older Adults. In: Bush, S.S. and Heck, A.L., Eds., Forensic Geropsychology: Practice Essentials, American Psychological Association, Washington DC, 117-133. https://doi.org/10.1037/0000082-007

[14] Heck, A.L. and Vauter, R. (2018) Assessment and Restoration of Competency to Stand Trial with Older Adults. In: Bush, S.S. and Heck, A.L., Eds., Forensic Geropsychology: Practice Essentials, American Psychological Association, Washington DC, 167-187. https://doi.org/10.1037/0000082-009

[15] Cressanthis, G.A. (1988) Criminal Homicide and the Elderly Offender: A Theoretical and Empirical Analysis. Journal of Quantitative Criminology, 4, 187-199. https://doi.org/10.1007/BF01062873

[16] Goetting, A. (1992) Patterns of Homicide among the Elderly. Violence and Victims, 7, 203-215. https://doi.org/10.1891/0886-6708.7.3.203

[17] Davoren, M., Fitzpatrick, M., Caddow, F., Caddow, M., O’Neill, C., O’Neill, H. and Kennedy, H.G. (2015) Older Men and Older Women Remand Prisoners: Mental Illness, Physical Illness, Offending Patterns and Needs. International Psychogeriatrics, 27, 747-755. https://doi.org/10.1017/S1041610214002348

[18] Carabellese, F., Candelli, C., Vinci, F., Tamma, M. and Catanesi, R. (2012) Elderly Sexual Offenders: Two Unusual Cases. Journal of Forensic Sciences, 57, 1381-1383. https://doi.org/10.1111/j.1556-4029.2012.02129.x

[19] Block, C.B. (2013) Homicide against or by the Elderly in Chicago 1965-2000. Homicide Studies, 17, 154-183. https://doi.org/10.1177/1088767913478596

[20] Putkonnen, H., Weizmann-Henelius, G., Repo-Tiihonen, E., Lindberg, N., Saarela, T., Eronen, M. and Hakkanen-Nyholm, H. (2010) Homicide, Psychopathology, and Aging-A Nationwide Registered-Based Case Comparison Study of Homicide Offenders Aged 60 Years and Older. Journal of Forensic Sciences, 55, 1552-1556. https://doi.org/10.1111/j.1556-4029.2010.01488.x

[21] Hunt, I.M., Swinson, A.B., Flynn, S., Haynes, A.J., Roscoe, A., Rodway, C., Shaw, J., et al. (2010) Homicide Convictions in Different Age-Groups: A National Clinical Survey. The Journal of Forensic Psychiatry \& Psychology, 21, 321-335. https://doi.org/10.1080/14789940903513195

[22] Durand, M.V. and Barlow, D.H. (2016) Essentials of Abnormal Psychology. 7th Edition, Cengage, Boston, MA. 
[23] Lyons, C.A. and Martin, B. (2014) Abnormal Psychology: Clinical and Scientific Perspectives. 5th Edition, BVT Publishing, Redding, CA.

[24] Schwarz, C. (2016) AARP Survey Highlights Prescription Drug Use among Older Adults. Medicare Rights.

https://blog.medicarerights.org/aarp-survey-highlights-prescription-drug-use-amon g-older-adults 